we close. When a case is seen early, before the urates have attacked the joints and all fibrous tissues so acutely, salicylate of soda, salicylic acid from ol. gaultheriæ and various salicylic compounds, have all proved more useful in my hands than any other remedies. But after the urates have entered the joints and fibrous tissues of the muscles, no medicine that I have ever found as yet will remove them in less than four to six weeks or until the acute inflammation subsides by limitation.

\section{CURIOUS FACTS YOU FIND IN GENERAL SURGERY.}

BY LUCIEN LOF'TON, A.B., M.D.

PRESIDENT SEABOARD MEDICAL ASSOCIATION OF VIRGINIA AND NORTII CAROLINA.

NORFOLK, VA.

\section{INJURY TO NEGRO'S HEAD.}

Not many months ago I was called into the country to see a negro who had been chopped in the head with an ax "during a friendly" bout. I found a seemingly inanimate form, lying prone on the ground, and oozing leisurely from a long wound on the side of the head and face were several streams of blood. The man had received the cut three hours before and nothing had been done to check the flow of blood. Negroes are a peculiar people. Under no circumstances would one have helped this poor fellow, from the fear of getting "mixed" up with the courts, although they were perfectly willing to look on and speculate on the final outcome of everything connected with the case. Upon a closer examination I found that the external temporal and the transverse facial arteries had been entirely severed, besides a number of peripheral arterial twigs. The outer and inner tables of the skull had been crushed, ranging from the upper portion of the temporal bone in an oblong direction, barely grazing the curvature of the malar bone, and covering altogether a gash measuring about $43 / 4$ inches. Internally the middle meningeal artery was severed. while the meninges suffered greatly. I suppose I removed one or two ounces of brain matter, which, owing to compression and laceration that existed, oozed quite freely. The inner table of the skull had been badly shattered and I removed several spicula of bone. The middle meningeal gave me a little concern at first, but was finally controlled by "plugging." How the lateral sinus was lost I suppose applies to a general distinction I make on occasions of this kind, i. e., that there is a special Providence who looks after babies, fools and drunkards. I used plain boiled water while preparing the toilet. A No. 1 fiddle-string was the ligature chosen for suturing the brain covering, while the skin flaps were closed by an uninterrupted suture, with a No. 2 catgut. At the extreme lower portion of the wound, which, when measured after having been closed, fell a fraction short of five inches, I inserted a few strands of gut. I did not even shave the parts surrounded by hair. The man's skin certainly appeared dirty and greasy enough, while the blood-matted hair bore every evidence of being otherwise than aseptic. I applied over the wound a piece of sterilized gauze moistened with a phenol-camphor preparation I use, comprising by weight equal parts of gum camphor, and crystallized phenol, the same being reduced to a liquid by trituration. Over this a bushy piece of plain sterilized gauze was placed, and an external bleached-cotton bandage. The man was put to bed in somewhat of a weakened condition. The next twenty-four hours was passed pleasantly, without a rise of temperature, and practically no soreness. In fortyeight hours he was on his feet, and in twelve days he had resumed his position as a saw-mill hand. On the fourth day I gave the wound the second dressing. It was clean and free from edema, and had no odor. I dismissed him with the third toilet, and his recovery was without the slightest interruption. During the process of the initial dressing I administered, hypodermically, 1/4 gr. of morphin sulphate, in connection with $1 / 60 \mathrm{gr}$. of strychnin nitrate, besides a little brandy, which was most graciously received.

I watched the man carefully for seven months and, seeing him only about a fortnight ago, he said he had never had the slightest impediment of any description, not even a headache or a twitching eye. Owing to the destroyed bone-tissue the full internal relationship existing between the layers of skull have never been replaced, and on palpation a well-marked indentation is felt.

This is a remarkable instance in general surgery, and while the final result is peculiar indeed, it also in a degree demonstrates what a lack of unnecessary probing and non-meddling will accomplish. If this had been a white man, no doubt he would have died. Just why such recoveries take place in negroes is a psychologic study.

There is one thing I wish to eall to the attention of the medical profession, and that is, where you have a lowered vitality resulting from shock and especially hemorrhage, and where it is inconvenient or impossible to administer a saline injection, use small doses of strychnin. I have seen many lives sacrificed by giving large doses of this.

\section{BROKEN RADIUS AND UNCONSCIOUS OF IT.}

A negro laborer came to my office and, exhibiting his forearm, said that he believed he had "caught cold" in it and it had resulted in rheumatism. On examination I found the radius entirely separated and got a distinct crepitus. I called his attention to the characteristic click. "Well," said he, "I believe I do remember while sawing wood about ten days ago that my arm gave way." From that time until he came to consult me, he had steadily held his position as "sawyer," working twelve hours a day with little or no inconvenience. Continual usage had made it sore and that is why he came. His parents had died with pulmonary consumption, also a sister and brother. His personal history might have been syphilitic, but owing to his disconnected story I left the question open. His long bones elsewhere were normal, as also were the short and flat ones. No specific history of syphilis was noted. There seems to have been a transverse fracture which was complete. He denied any fight, fall, wrench, or trauma. I tried in vain the suspected friability of other bones, but found in every one evidence of perfect soundness. His general condition was good, and to all appearances he was a fine specimen of manhood. No valvular trouble existed, and no lingering diseases of any kind were elicited. On manipulation little if any pain was evinced. I adjusted the parts, and immediately applied three 1-inch strips of adhesive plaster around the forearm. This held the bones firmly in place. Next I applied a snugly-fitting veneer roller splint, and throwing around this additional strips of plaster, I ultimately made the splint more secure by an outer, spiral cotton bandage. I purposely avoid a "pistol-handle" splint for cases of this kind. It may be warranted in some rare instances, but Nature has to do a great deal after you remove it. I speak from practical experience, for I have personally helped to 
swell the list of reported Colles' fractures. Many use plaster-of-Paris dressing, which I admit is a very nice way to put up a fracture of this kind, but it has its defects by being hard to regulate flexion and extension of che fingers, while the thumb fares better than its neighbors. Then again it is quite difficult to remove, in case of accident or for a change. All fractures should be kept in sight of the surgeon if possible. Sometimes nothing can be substituted for the plaster-of-Paris splint, and here they are useful. Any one trying a simple splint on Colles' fracture will be surprised at the result.

I dismissed the patient in twenty days. In five thereafter he again began the task of sawing down trees, and he reports his right arm as good as it ever was. The only internal treatment I gave was a U. S. P. lime-water to be drunk in place of all other water for thirty days. There was no "silver fork" deformity, no pain at the seat of injury, or no perceptible displacement of the bones. All in all, this was very interesting and unusual, and up to this writing, which covers a period of months, no recurrence of the trouble has been noted.

CORNU CUTANEUM.

In the early part of 1897 , a man of about 70 years, came to me, presenting rather a peculiar growth on the upper portion of his face, immediately in front of the right auricle. He stated he had had it on the face for nearly a half decade, but by an occasional paring the growth was kept in abeyance. No trouble or pain had arisen as a result of the excresence, and its being unsightly was the cardinal excuse for wanting it removed. I removed it under cocain anesthesia, curetted the core, and brought the flaps in approximate relation. The base was in close proximity to the temporal artery. The wound healed kindly within a week, but I saw my patient some three months afterward, and springing from the original core was another horn. This was removed together with all horny cells, which resulted in a complete enucleation.

Sailors are especially prone to cutaneous horns, although this man had never followed a seafaring life. The less pigment you find in people, the more susceptible they are to all manner of cutaneous affections. This applies to verruce, various dermal tumors and hypertrophies generally. Unless you thoroughly remove every vestige from which cutaneous horns grow, they will return and often multiply, much to your and the patient's chagrin.

Practically very little is written regarding the pathology of cornu cutaneum. Hyde, among others, claims horns are composed of more or less concentrically disposed epidermal cells, with nuclei as a rule. They may result from friction, pre-existing lesions and heredity, though the latter is a mooted question. The tissue is as genuine a horn growth as you find in the lower animal, notwithstanding many contrary opinions.

SHATTERED HUMERUS AT THE LOWER THIRD, INVOLVING THE JOINT.

Two years ago a mother, attended by a delegation of relatives, friends and acquaintances, brought to my office a white boy about 10 years of age, with a broken and shattered humerus at the lower third, which involved the elbow-joint. The boy had received the injury while playing, and attempting to scale a high plank fence he lost his balance. The bone was badly broken, and when I made the initial examination, it had been done three weeks. The family had waited for the inflammation to subside, as the mother very evasively remarked. Spiculæ of bone almost penetrated the outer skin-covering, and were making good headway for an external opening when
I first saw it. The next day I operated, with the assistance of two colleagues. On cutting down I removed several pieces of chipped bone, and during this process a dark bloody exudate ran freely. The portions of bones already noted, that appeared immediately under the integument, were removed easily with bone forceps. The entire shaft of the humerus was traversed by considerable inflammation, but the lower surgical third was more or less involved in the fracture, and made it necessary to do some wire suturing. Although the joint was involved to the extent of partial ankylosis, due to a deposit of fibrin resulting from the trauma, it was carefully opened, washed out with warm sterilized water and closed, without drainage. The same applies to the fractured humerus. Both places healed by primary intention, without any trouble, and in the course of a month the splint was removed and the member allowed perfect freedom. A slight anklyosis existed for some six or eight weeks, but this was easily reduced by repeated hotair baths at a temperature of $300 \mathrm{~F}$. The boy was seen six weeks ago, and his arm appeared perfectly sound, with little, if any, sign of the operation remaining. Chloroform (Squibb's) was the anesthetic administered, and only one-half ounce was used, the operation being completed in eighteen minutes.

In closing I wish to make some comment on opening joints. With regard to joints treated surgically within the past fifty years, a great deal of importance has been given the propriety of freely operating in and about articular surfaces. I think each year brings us nearer to the point of confessing that joints may be invaded with impunity and with the knowledge of no ill results. Such at least has been my experience. A good many orthopedic men to-day decry the reckless manipulation of joint surfaces, which I will concede is orthodox surgery; but I think the reason has been, not so much on account of the mere invasion of joints, but because such corrosive fluids have been used hereabouts and within them, that bad results have obtained. It is bad surgery to use any corrosive antiseptic in an articular surface. Ninety per cent. of carious sockets will recover by injecting sterilized water, and at the same time you will have fewer ankylosed joints to deal with. I believe firmly in the limited value of antiseptic surgery, but it is carried too far.

230 North Park Avenue.

\section{PATHOLOGIC CHANGES OCCURRING IN THE UNOBSTRUCTED NOSTRIL IN CASES OF DEVIATED SEPTUM.*}

BY E. LARUE VANSANT, M.D.

Professor of Diseases of the Throat and Nose, Philadelphia Polyclinic; Physician to the Throat, Nose and Ear Department of the Howard Hospital, etc. PHILADELPHIA.

When only one of the nasal chambers is obstructed by a notable deviation of the septum, the immediate effect produced is a relative increase in the amount of respired air passing through the unobstructed nostril. This increased respiration through the unobstructed nostril causes increased functional activity of the mucous membrane and deeper structures, in order that the inspired air may be properly warmed and moistened. Such increased functional activity necessarily causes hyperemia of the parts, particularly of the tissues constituting the middle and inferior turbinal bodies. The increased blood-supply, together with the enlargement and pro-

*Read before the Eastern Bection of the American Laryngological, Rhinological and Otological Society, Philadelphia. 